\title{
AVALIAÇÃO DO CONSUMO ALIMENTAR DE PROTEÍNAS EM IDOSOS RESIDENTES NA CIDADE DE LIMEIRA-SP
}

\author{
Beatriz Peres Spagnol*, Gabriela Bragagnola, Bruna Zeferino Mathias, Graziele Maria da Silva, Carolina Neves \\ Freiria, Larissa Miho Hara, Ligiana Pires Corona.
}

\section{Resumo}

O objetivo do presente trabalho foi avaliar quantitativamente o consumo alimentar de proteínas na dieta de idosos participantes do programa de estratégia da saúde da família e residentes na cidade de Limeira-SP. Foram coletados dados sociodemográficos e de saúde de 157 idosos e o consumo de proteínas nas refeições foi avaliado através da aplicação de um recordatório de 24 horas. O consumo inadequado de proteínas mostrou-se associado significativamente à variáveis sociodemográficas e de saúde. Faz-se necessário conhecer o consumo alimentar dos idosos, assim como identificar o estado nutricional desses indivíduos, para que haja direcionamento de políticas públicas e orientação dos profissionais no cuidado desta população.

Palavras-chave: Idoso, consumo, proteína.

\section{Introdução}

Estudos recentes apontam a proteína como nutriente chave na promoção de saúde nos idosos e o consumo dietético maior do que as recomendações já estabelecidas nessa fase da vida tem mostrado melhora no processo de envelhecimento ${ }^{1}$. Com base em um conjunto crescente de evidências de dados epidemiológicos e experimentais, vários grupos de especialistas argumentam que uma maior quantidade de proteína de $1,0 \mathrm{~g}$ a $1,5 \mathrm{~g} / \mathrm{kg}$ de peso/dia pode ser ótima para o músculo esquelético e a saúde geral em idosos ${ }^{1}$. O objetivo do presente trabalho é avaliar o consumo alimentar de proteínas e seus fatores associados em idosos da cidade de Limeira-SP.

\section{Resultados e Discussão}

Foram entrevistados 157 idosos, sendo coletados dados sociodemográficos, de saúde e realizado a aplicação de um recordatório de 24 horas. Foram considerados como valores de referência para o consumo de proteínas valores $\geq 1,0 \mathrm{~g} / \mathrm{kg} / \mathrm{dia}$.

O consumo médio de proteína pela população do estudo $(n=157)$ foi de $67,3 \mathrm{~g}$, sendo significativamente maior entre homens do que mulheres $(61,4 \mathrm{~g}$ e $83,1 \mathrm{~g} ; \mathrm{p}<0,005)$.

Tabela 1. Prevalência de inadequação do consumo de proteína ( $\mathrm{g} / \mathrm{kg}$ de peso) relacionado a variáveis socioeconômicas e de estado nutricional dos idosos participantes de Limeira - SP.

\section{n Inadequado Valor}

(\%) $\quad p$

\begin{tabular}{|c|c|c|c|}
\hline \multicolumn{4}{|l|}{ Gênero } \\
\hline Feminino & 114 & 69,30 & - \\
\hline Masculino & 43 & 5116 & $0,034^{* *}$ \\
\hline \multicolumn{4}{|l|}{ Faixa etária } \\
\hline 60 a 69 anos & 82 & 64,63 & - \\
\hline 70 a 79 anos & 63 & 57,14 & - \\
\hline$\geq 80$ anos & 11 & 100 & $0,024^{*}$ \\
\hline \multicolumn{4}{|c|}{$\begin{array}{l}\text { Insegurança alimentar } \\
\text { por falta de dinheiro }\end{array}$} \\
\hline Não & 145 & 62,07 & - \\
\hline Sim & 12 & 91,67 & $0,057^{*}$ \\
\hline \multicolumn{4}{|l|}{ IMC } \\
\hline Desnutrido & 6 & 33,33 & - \\
\hline Eutrófico & 57 & 54,39 & - \\
\hline Sobrepeso & 94 & 72,34 & $0,016^{*}$ \\
\hline
\end{tabular}

\begin{tabular}{cccc}
\hline $\mathrm{CC}^{+}$ & & & \\
\hline Sem risco & 60 & 51,67 & - \\
\hline Risco & 96 & 72,92 & $0,007^{* *}$ \\
\hline
\end{tabular}

${ }^{*}$ teste exato de Fisher ${ }^{* *}$ qui quadro de Pearson ${ }^{+}$circunf. cintura

De acordo com a Tabela 1 o consumo inadequado de proteínas teve associação significativa com as variáveis socioeconômicas e de estado nutricional. Foi observado que as mulheres têm um consumo mais inadequado de proteína do que os homens, assim como visto num estudo de base populacional de Porto Alegre ${ }^{2}$. Todos os idosos com 80 anos ou mais apresentaram inadequação do consumo do macronutriente, o que pode estar associado a anorexia do envelhecimento, que é caracterizada pela inapetência e baixa ingestão alimentar que ocorre com frequência em idosos longevos ${ }^{3}$.

Também é possível notar que $91 \%$ dos idosos com insegurança alimentar referiram ingestão inadequada de proteína. Os indivíduos com sobrepeso são os que mais demonstraram consumo inadequado de proteína, o que pode estar relacionado com o fato de que as proteínas influenciam diretamente no esvaziamento gástrico e aumento da saciedade ${ }^{5}$.

\section{Conclusões}

O consumo alimentar de proteína é influenciado por diversos fatores, bem como são vistos nos resultados apresentados. Grande parte dos idosos estudados apresentam inadequação no consumo do macronutriente, o que pode repercutir no processo de envelhecimento e qualidade de vida desta população.

\section{Agradecimentos}

Agradeço pelo apoio do CNPQ e Ministério da Saúde, assim como ao PIBIC pela bolsa de Iniciação Científica.

\footnotetext{
${ }^{5}$ Bell, E. A.; Rolls, B. J.; Energy density of foods affects energy intake across multiple levels of fat content in lean and obese women. Am. J. Clin. Nutr. 2001.

${ }^{1}$ Franzke, B.; Neubauer, O.; Cameron-Smith, D.; Wagner, K. Dietary Protein, Muscle and Physical Function in the Very Old. Nutrients. 2018.

${ }^{3}$ Morley, J.E.; Silver, A.J. Anorexia in the elderly. Neurobiology of Aging, Vol. 9, pag 9-16. Pergamon Journals Ltd., 1988.

${ }^{4}$ Silva, C. C. S., Oliveira, K. B. B., Alves, A. D. S., Neves, J. A., Modesto, C. A C., \& Vianna, R. P. D. T. Associação entre consumo alimentar e (in) segurança alimentar e nutricional em São José dos Ramos-PB. Brazilian Journal of Food Technology. 2012.

${ }^{2}$ Venturini, C. D.; Engroff, P.; Sgnaolin, V.; Kik, R. M. E.; Morrone, F. B.; Silva Filho, I. G. D.; Carli, G. A. D. Consumo de nutrientes em idosos residentes em Porto Alegre (RS), Brasil: um estudo de base populacional. Ciência \& Saúde Coletiva. 2015.
} 